\title{
Cilio-retinal infarction after retinal vein occlusion
}

\author{
D. M CLEOD AND C. P. RING* \\ From Moorfields Eye Hospital, Lonton
}

Cilio-retinal arterioles are branches of the posterior ciliary arteries which supply areas of inner retina contiguous with the optic disc in about 20 per cent of individuals (Hayreh, 1963a). The cilio-retinal territory is spared from ischaemic necrosis after occlusion of the central retinal artery, while infarction of retina supplied by cilio-retinal arterioles may accompany ischaemic swelling of the disc when the posterior ciliary arteries are occluded in temporal arteritis (Hayreh, 1969).

Only two cases of retinal infarction in the cilioretinal distribution have so far been described in association with occlusion of the central retinal vein (Oosterhuis, 1968; Hayreh, 1971), although such cases are not rare. The purpose of this paper is to present a series of 10 further cases together with a case of cilio-retinal infarction associated with a hemisphere branch retinal vein occlusion. The interrelationships between retinal vein occlusion and impaired posterior ciliary perfusion are discussed in the light of our findings.

*Supported by the Prevention of Blindness Research Fund

Address for reprints: D. McLeod, FRCS, Moorfields Eye Hospital, City Road, London ECIV 2 PD

\section{Patients and methods}

The I I patients were drawn from the ophthalmic practice in Moorfields Eye Hospital (MEH), St Thomas's Hospital (STH), the Edinburgh Royal Infirmary (ERI), and the National Hospital, Queen Square (NHQS) (Table). Six patients were observed personally by one or other of us, while in the remaining cases we referred to case records and photographs. Fluorescein angiography was performed by the routine technique of the department concerned, in which Io or 20 per cent fluorescein solution was injected into an antecubital vein. Photographs were generally taken at intervals of one second during the initial dye transit, using a Zeiss (Oberkochen) fundus camera. In all cases the initial photographic assessment was carried out within two weeks of the onset of symptoms and in seven cases within three days of visual loss. A medical examination and systemic investigation were carried out in most patients but were not standardized. Similarly, visual fields were tested by a variety of routine clinical techniques.

\section{Results}

CENTRAL RETINAL VEIN OCCLUSION (Cases I-IO)

The patients noticed sudden visual deterioration in one eye, and several complained specifically of a

Table Particulars of I I cases of cilio-retinal infarction

\begin{tabular}{|c|c|c|c|c|c|c|c|c|c|c|}
\hline \multirow{2}{*}{$\begin{array}{l}\text { Case } \\
\text { no. }\end{array}$} & \multirow{2}{*}{$\begin{array}{l}\text { Fig. } \\
\text { no. }\end{array}$} & \multirow[b]{2}{*}{ Source } & \multirow{2}{*}{$\begin{array}{l}\text { Age } \\
\text { (years) }\end{array}$} & \multirow[b]{2}{*}{ Sex } & \multirow{2}{*}{$\begin{array}{l}\text { No. of } \\
\text { cilio-retinal } \\
\text { arterioles }\end{array}$} & \multirow[b]{2}{*}{ Eye } & \multicolumn{2}{|c|}{ Visual acuity } & \multirow{2}{*}{$\begin{array}{l}\text { Systemic } \\
\text { disease }\end{array}$} & \multirow{2}{*}{$\begin{array}{l}\text { Blood } \\
\text { pressure } \\
(\mathrm{mmHg})\end{array}$} \\
\hline & & & & & & & At onset & At one year & & \\
\hline $\mathbf{I}$ & I & STH & 35 & Male & 3 & Left & $6 / 60$ & $6 / 4$ & 一 & $120 / 90$ \\
\hline 2 & 2 & MEH & 79 & Female & $\mathbf{I}$ & Right & CF & PL & $\begin{array}{l}\text { Cerebrovascular } \\
\text { insufficiency }\end{array}$ & $190 / 100$ \\
\hline 3 & 3 & MEH & 41 & Female & 2 & Right & $6 / 24$ & $6 / 6$ & Migraine & $140 / 80$ \\
\hline 4 & 4 & MEH & 69 & Male & $\mathbf{I}$ & Left & $\mathrm{CF}$ & CF & - & $120 / 70$ \\
\hline 5 & $*$ & STH & 50 & Male & 2 & Right & $6 / 60$ & $6 / 12$ & Angina pectoris & $110 / 70$ \\
\hline 6 & $t$ & ERI & 52 & Female & 4 & Right & $6 / 18$ & $6 / 4$ & - & $110 / 70$ \\
\hline 7 & $\ddagger$ & MEH & 75 & Female & 2 & Right & $6 / 24$ & PL & - & $160 / 90$ \\
\hline 8 & & $\mathrm{MEH}$ & 32 & Male & 2 & Left & $6 / 18$ & $6 / 9$ & 一 & I $10 / 90$ \\
\hline 9 & & MEH & 69 & Female & 2 & Right & CF & CF & $\begin{array}{l}\text { Hypertension } \\
\text { (on treatment) }\end{array}$ & $170 / 100$ \\
\hline 10 & & NHQS & 69 & Female & 3 & Right & $6 / 60$ & $6 / 18$ & Arteriosclerosis & $130 / 80$ \\
\hline I I & 5 & MEH & 39 & Female & 2 & Left & $6 / 18$ & $6 / 12$ & - & I $50 / 90$ \\
\hline
\end{tabular}

* Fig. 4 in McLeod (1975b); †Fig. 1 in McLeod (1975a); $\ddagger$ Fig. 6 in McLeod (1976)

$\mathrm{CF}=$ counting fingers; $\mathrm{PL}=$ perception of light 


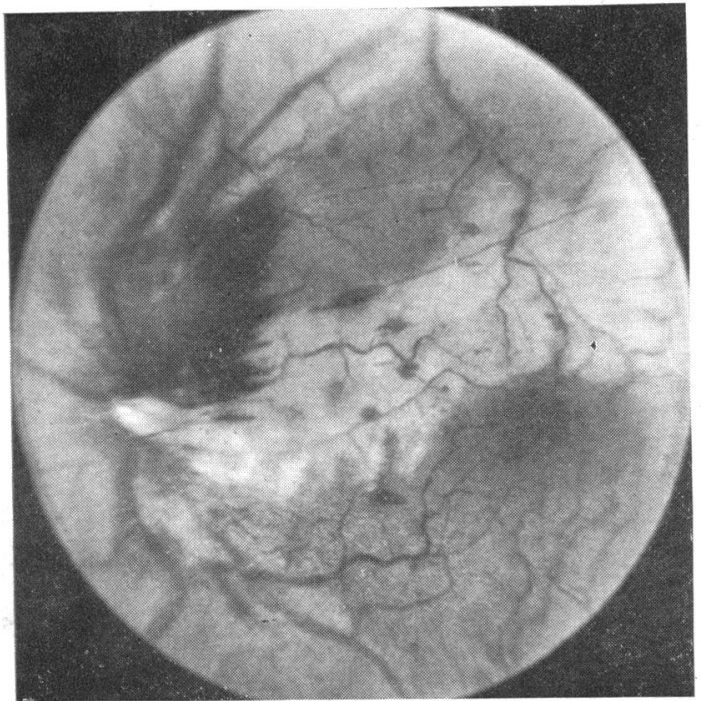

$(\mathrm{I} a)$

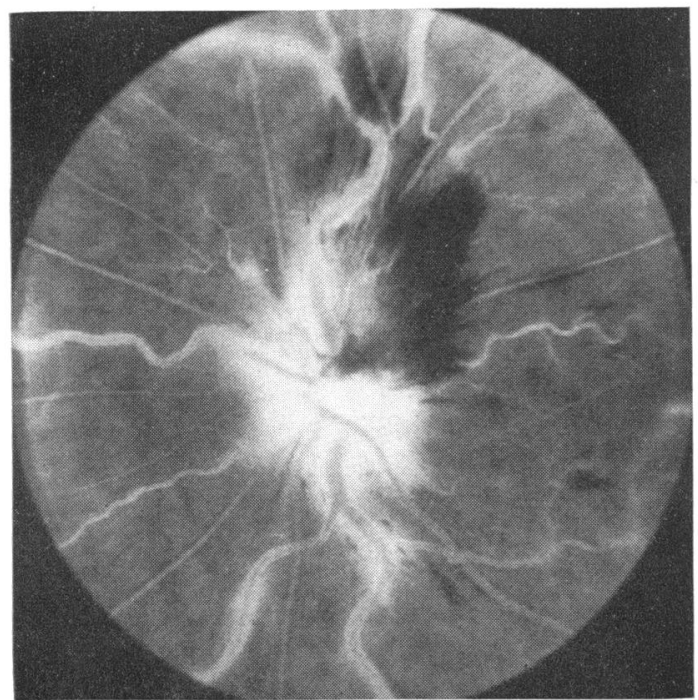

(IC)

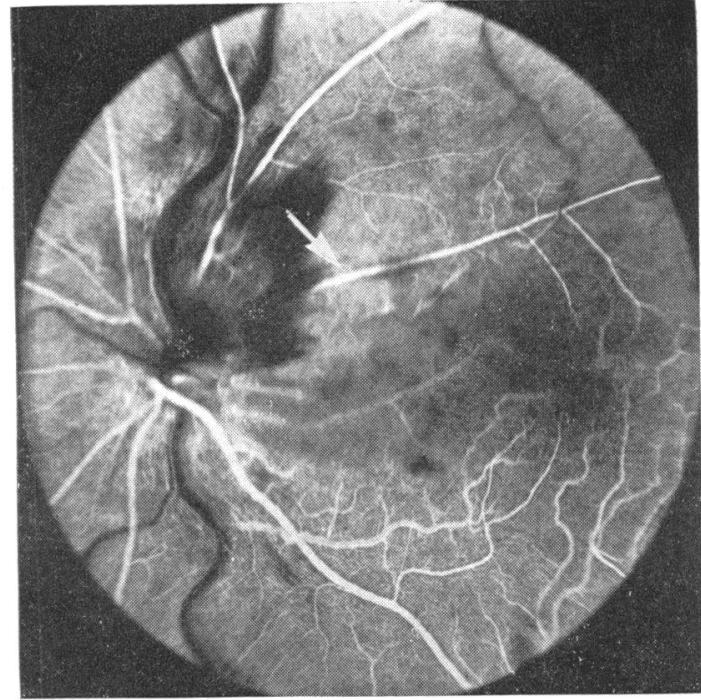

$(\mathrm{r} b)$

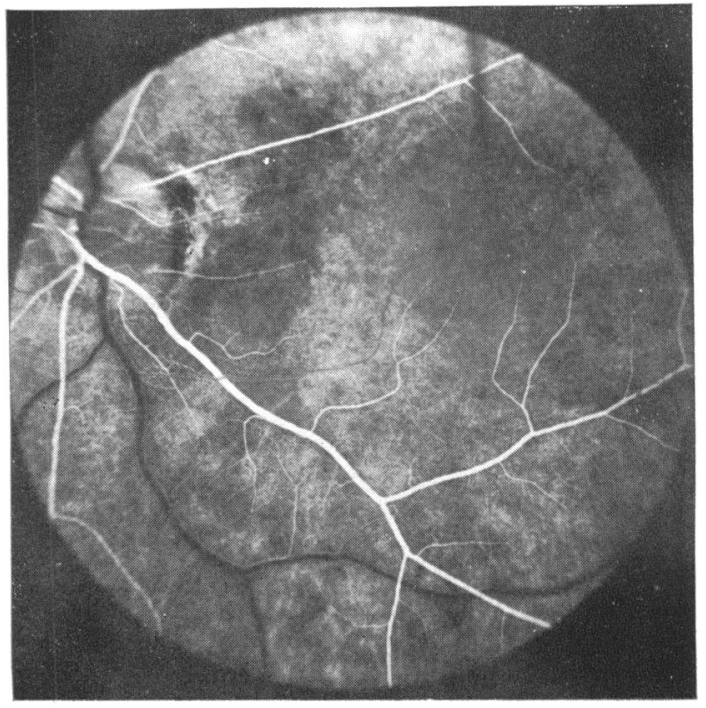

( $\mathrm{I} d)$

FIG. I Case I. (a) Fundus photograph Io days after visual loss : retinal infarction in cilio-retinal territories.

(b) Fluorescein angiogram (same study as (a)) : early arterio-venous phase, larger cilio-retinal arteriole (arrow) has filled. (c) Fluorescein angiogram (same study as (a)): late phase, dye leakage from disc and veins. (d) Fluorescein angiogram seven months later : early arterio-venous phase, delayed peripapillary choroidal filling

localized scotoma in the central field of vision. Pre-existing ocular lesions had been discovered in only one patient (case 2), who was known to have had bilateral preretinal macular fibrosis for six years.

\section{Anterior segment}

On presentation there was no significant abnormality in the anterior segment or ocular media of any patient; in particular, there were no inflam- matory signs in the aqueous or anterior vitreous. Apart from a single patient with mild chronic glaucoma (case 9), the intraocular pressure was normal in each eye, though the pressure in the affected eye was generally $2-4 \mathrm{mmHg}$ less than that in its fellow.

\section{Presenting fundus signs}

Funduscopy showed widespread retinal haemorr- 
hages (including blot haemorrhages anterior to the equator) together with distension and tortuosity of all tributaries of the central retinal vein (Fig. I). Some patients showed occasional perivenous cottonwool spots or retinal oedema, especially at the macula.

In addition to signs of central vein occlusion, retinal pallor was seen contiguous with the optic disc, and parts of the periphery of these areas showed an intense whiteness. The clinical appearance was that of ischaemic cloudy swelling of the inner retina. The infarcts comprised the territories of supply of cilio-retinal arterioles, and in the eight patients with multiple cilio-retinal vessels each cilio-retinal territory was infarcted. Haemorrhages were present within the infarcts but were generally few in number, except in case 2 (Fig. 2).

There was variable swelling of the optic nerve head on presentation (Figs I, 3), and marked disc pallor was observed in case 7 and in the lower half of the disc in case 4 (Fig. 4). Papillary haemorrhages were conspicuous in some cases, but absent in others (Figs I, 3).

\section{Fluorescein angiography}

The intraretinal circulation time (from dye appearance in the central artery to filling of the major veins at the optic disc) exceeded eight seconds in all cases. The central retinal capillary bed was engorged and fluorescein often leaked from venules or larger veins in the late phases (Figs 1,2 ).

Fluorescein perfusion through the cilio-retinal circulation was consistently impaired relative to central arterial perfusion, and the arrival of fluorescein in cilio-retinal arterioles was never observed to precede the arrival of dye in the central artery. The cilio-retinal vessels contained dye in the first available frame of the central arterial transit in seven cases, while cilio-retinal arteriolar filling was delayed in cases 6,9 , and 10. In four patients (cases $1,5,6$, and 8) an intact, engorged cilio-retinal microcirculation was demonstrated with occasional knob-like capillary dilatations resembling microaneurysms. In the remaining six cases the advancement of dye along the cilioretinal arterioles was very slow, and reversal of flow (Fig. 3c) was seen in cases 2, 3, 7, and 9. The lack of capillary pattern and dye leakage clearly distinguished the cilio-retinal territory from the central retinal supply (Fig. 2) and venules crossing the infarct filled with dye from the adjacent circulation. Retrograde entry of dye into the cilioretinal capillary bed was sometimes seen in these cases (Fig. $3 c$ ).

Angiographic assessment of the posterior ciliary circulation to the optic disc was often difficult because of haemorrhage, but delayed filling of the

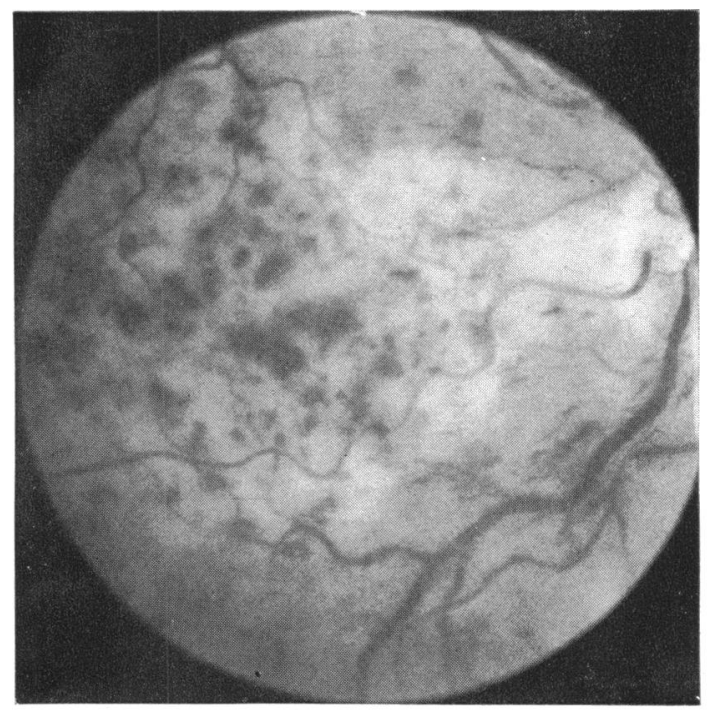

(2a)

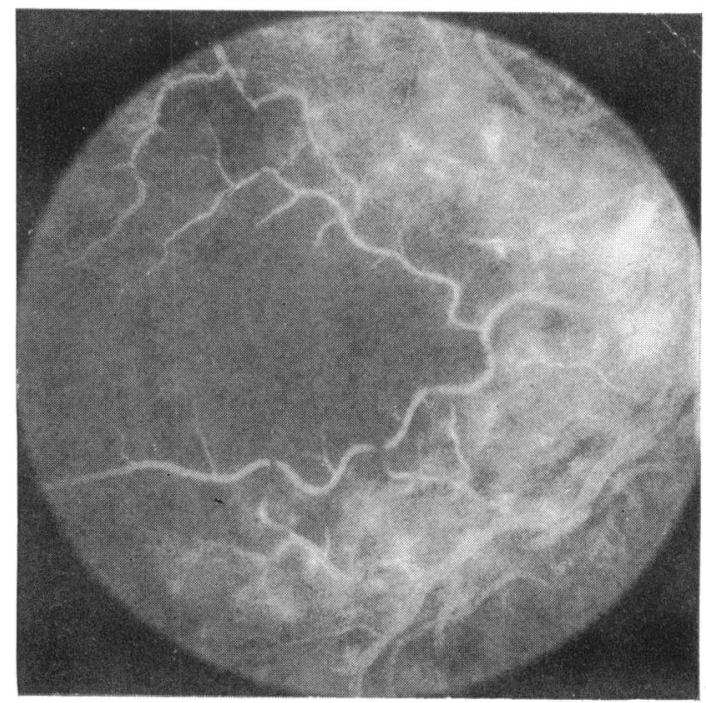

$(2 b)$

FIG. 2 Case 2. (a) Fundus photograph three days after visual loss: haemorrhagic cilio-retinal infarct. (b) Fluorescein angiogram: late phase, dye leakage from venules in central arterial territory

disc microcirculation was sometimes demonstrable (Fig. 3). There was variable late leakage of dye from the optic disc (Figs I, 3).

\section{Visual function}

The presenting visual acuities in the affected eyes are shown in the Table. Although cloudy retinal swelling involved the papillo-macular bundle in all cases, central fixation was preserved except in case 2 , 


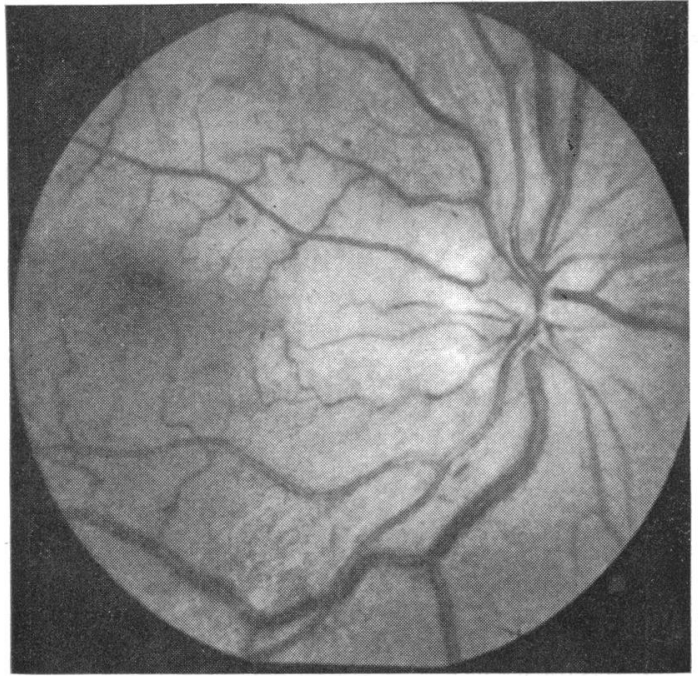

(3a)

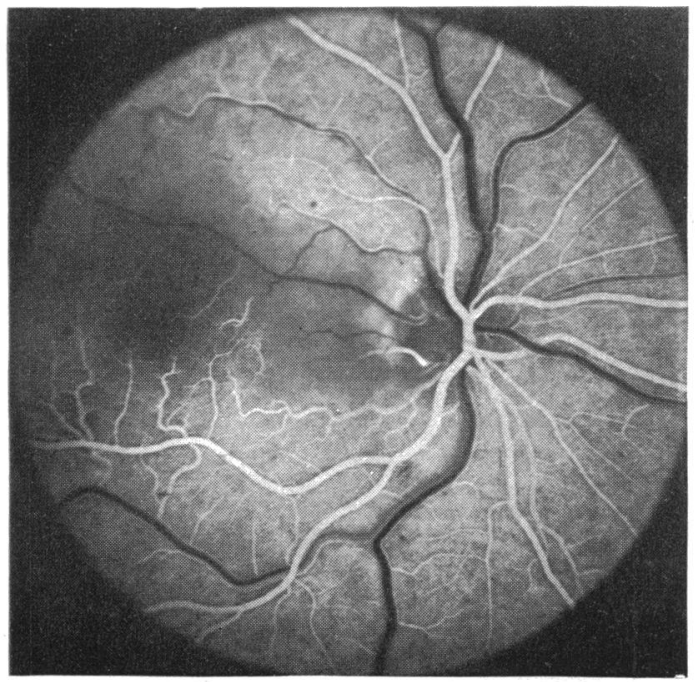

(3c)

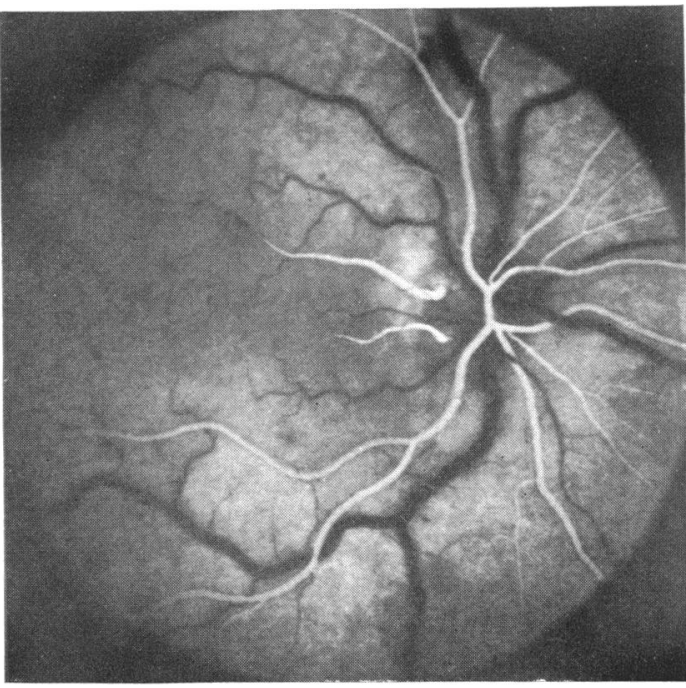

(3b)

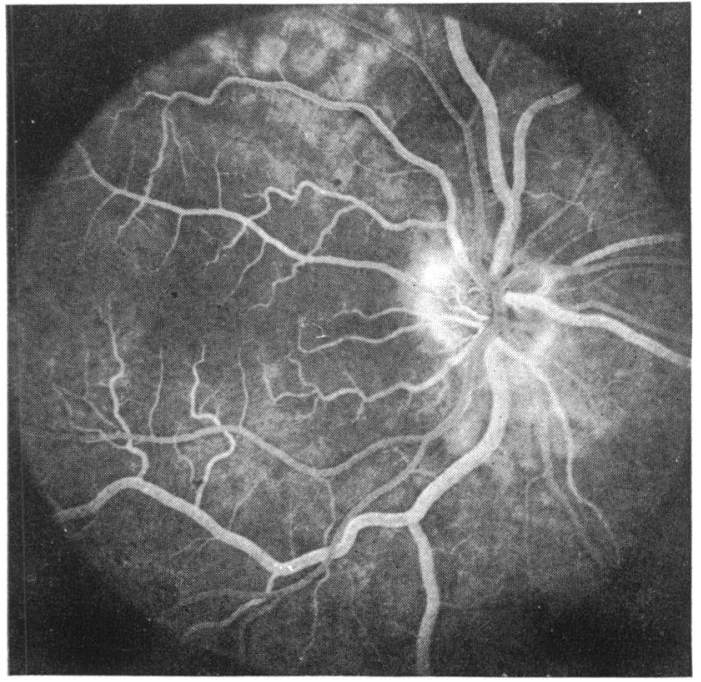

(3d)

FIG. 3 Case 3. (a) Fundus photograph one day after visual loss : mild ischaemic disc swelling, cilio-retinal infarcts and venous distension. (b) Fluorescein angiogram: retinal arterial phase, truncated dye front in cilio-retinal arterioles.

(c) Fluorescein angiogram: early arterio-venous phase, reversal of flow in cilio-retinal arterioles, optic disc not filled.

(d) Fluorescein angiogram : late phase, minimal disc-leakage

in which a large cilio-retinal arteriole supplied most of the posterior retina (Fig. 2).

Visual field examination revealed absolute scotomata which extended from the blind spot and corresponded with the distribution of retinal infarction. The scotoma split fixation in cases I, 3, 4, 5, and 7 because the cilio-retinal supply contributed to the perifoveal capillary arcade. In addition to these absolute defects, field loss in the remaining visual field reflected retinal oedema and haemorrhage or optic nerve head ischaemia. An extensive upper field defect in case 4 , for example, resulted from infarction of the lower half of the optic disc.

\section{General medical examination}

Systemic disorders found in the patients and possibly significant in the aetiology of their ocular vascular occlusions are shown in the Table. There was no evidence of temporal arteritis in any patient. 


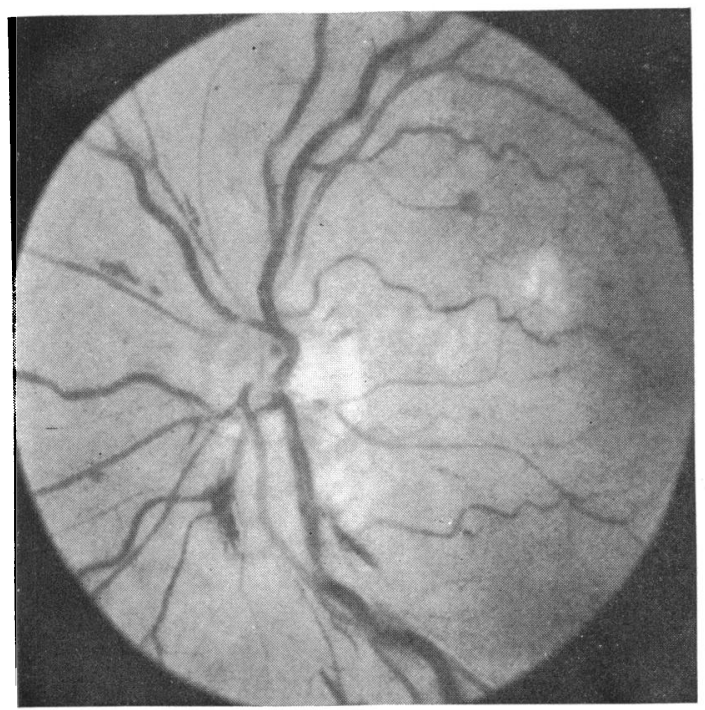

$(4 a)$

FIG. 4 Case 4. (a) Fundus photograph three days after visual loss: accumulations of axoplasmic debris in retina (two cotton-wool spots) and inferonasally on disc. (b) Fundus photograph five months later: optic atrophy except superonasally. (c) Fluorescein angiogram (same study as (b)) : retinal arterial phase, delayed filling of disc vessels, peripapillary choroid, and cilio-retinal arteriole

\section{Course}

Rubeotic glaucoma developed within three months of presentation in two patients (cases 2 and 7). In the remaining eight cases venous distension subsided within a few weeks, with absorption of retinal haemorrhages and oedema. Visible retinociliary venous bypass channels developed in five patients (cases $1,3,5,6$, and 10 ) and six patients showed some improvement in central vision (Table). The optic disc swelling subsided and localized sectors of pallor of the disc reflected ascending optic atrophy secondary to cilio-retinal infarction; atrophy and cupping of the lower half of the disc was seen in case 4 (Fig. 4).

Although no unequivocal angiographic evidence of impaired choroidal perfusion had been found on presentation, retinal haemorrhages and oedema made the initial assessment difficult and delayed peripapillary choroidal filling was demonstrated in cases I, 4, 5, and 6 on follow-up (Figs I, 4).

\section{HEMISPHERE BRANCH RETINAL VEIN OCCLUSION} (Case I I)

A 39-year-old woman noticed sudden blurring of vision in her left eye the day before presentation.

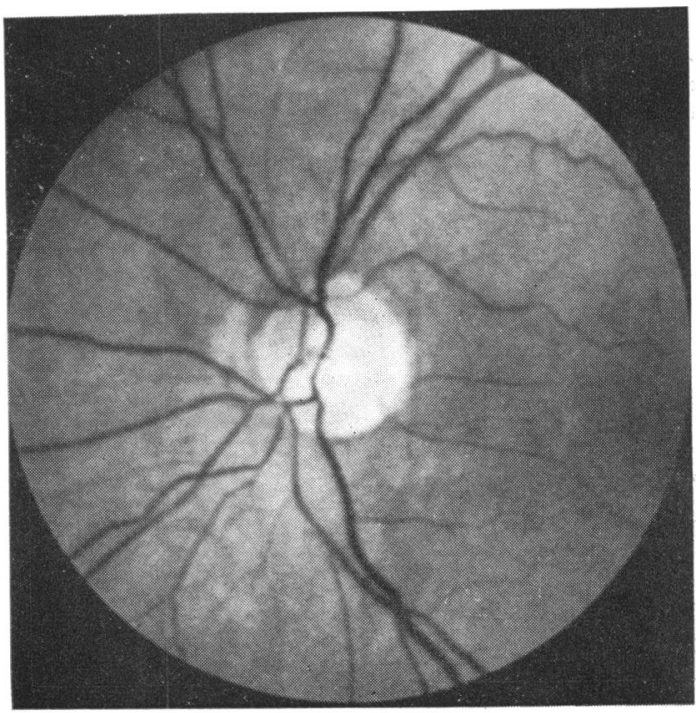

$(4 b)$

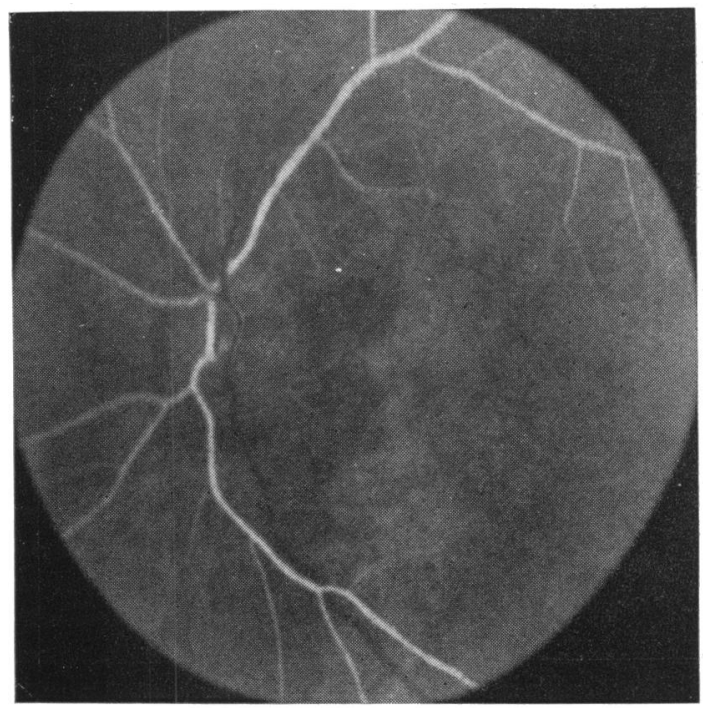

$(4 c)$

Funduscopy showed distension and tortuosity of the veins draining the superior retinal hemisphere. The upper rim of the optic disc was swollen and cloudy retinal swelling was seen in the superior macular area. The retinal infarct consisted of that part of the cilio-retinal circulation which drained into the obstructed vein (Fig. 5). Fluorescein angiography revealed extremely slow perfusion of a dilated capillary bed within the ischaemic area. However, the cilio-retinal territories drained by the inferotemporal branch vein filled satisfactorily with dye and showed no cloudy swelling or related field defect.

Signs of venous obstruction subsided within a 


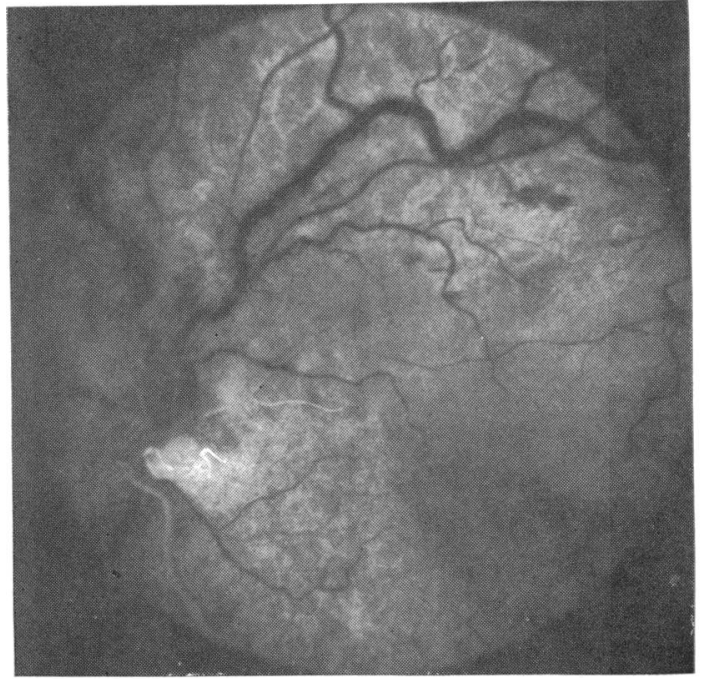

$(5 a)$

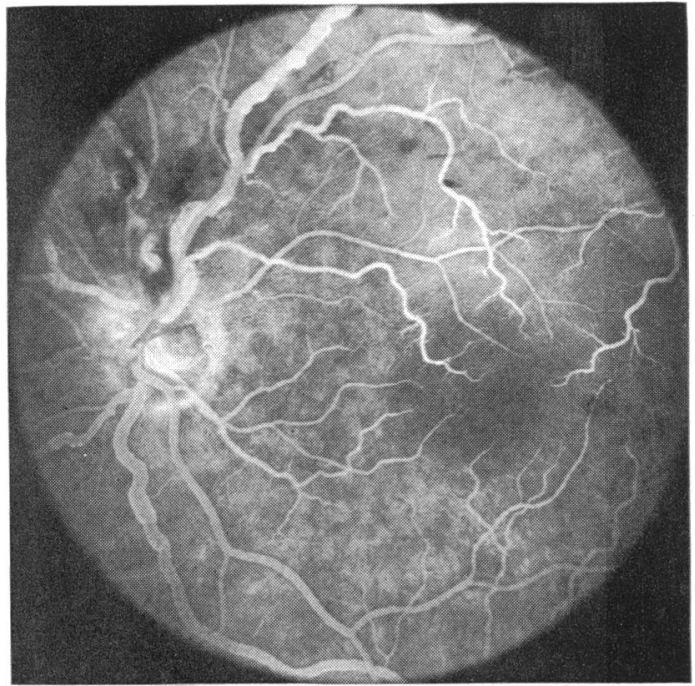

$(5 c)$

few weeks without treatment and left no sequelae apart from a permanent scotoma below fixation, localized retinal atrophy, and slight sectoral disc pallor.

\section{Discussion}

CLINICAL PICTURE

The patients in this series presented a varied clinical picture typical of acute retinal vein occlusion. Several cases conformed to the description of venous obstruction in youth and middle age designated 'retinal vasculitis' by Lyle and Wybar (I96I), 'papillophlebitis' by Lonn and Hoyt (1966), and 'optic disc vasculitis' by Hayreh (1972).

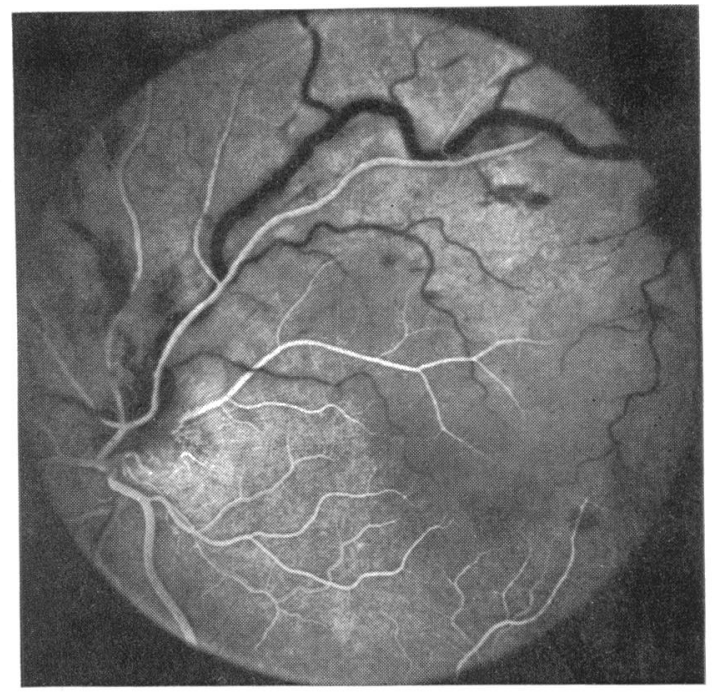

$(5 b)$

FIG. 5 Case I I. Fluorescein angiograms one day after visual loss. (a) Preretinal arterial phase, masking of choroidal fluorescence by retinal oedema, lower branch of upper cilio-retinal arteriole has filled. (b) Retinal arterial phase in drainage area of superior hemisphere vein, retinal venous phase in drainage area of inferior hemisphere vein. (c) Late phase, dilated capillaries in ischaemic area, slight disc leakage.

These patients illustrated the characteristic tolerance of a young microcirculation to raised intraluminal pressure and showed a tendency for spontaneous recovery without treatment, which has been attributed to the facility for developing retino-ciliary bypass channels (Hart, Sanders, and Miller, 1971). However, rubeotic glaucoma, a frequent complication of central vein occlusion, developed in two elderly patients in the series.

Retinal pallor, corresponding absolute visual field defects, and grossly retarded perfusion by fluorescein provided unequivocal clinical proof of ischaemic cloudy swelling in the cilio-retinal territories. This was also suggested by the signs of accumulated axoplasmic debris at the periphery of the infarcts (McLeod, 1975a) and the subsequent localized inner retinal atrophy with loss of superficial reflexes from nerve-fibre bundles. However, the ischaemic retina in these cases differed in certain respects from infarcts due to 'pure' arteriolar occlusion. Haemorrhages, for example, were present within the cilio-retinal territories and were extensive in a patient who had pre-existing disease of the macular capillary bed (case 2, Fig. 2). In addition the cilio-retinal circulation was demonstrably en- 
gorged in some cases and capillary dilatations resembling microaneurysms were also seen.

In no case of central vein occlusion have we observed retinal infarction localized to the territory of a branch of the central retinal artery, so this complication appears to be a development peculiar to the cilio-retinal circulation. This must reflect the independent origin of cilio-retinal arterioles from the posterior ciliary vessels. However, relatively few patients with cilio-retinal arterioles who suffer a central vein obstruction develop retinal infarction in the cilio-retinal territories (McLeod, I975b). The two groups of patients (that is, those with and those without cilio-retinal infarction) cannot be distinguished either by the severity of venous obstruction or by the size of their cilioretinal vessels.

\section{CIRCULATORY PHYSIOLOGY}

The intraluminal pressure in the major ocular veins $\left(\mathrm{P}_{\mathrm{v}}\right)$ normally approximates to the intraocular pressure $\left(\mathrm{P}_{i \mathrm{o}}\right)$, probably owing to changes in crosssectional diameter of these vessels as they leave the globe-a vascular waterfall (Permutt and Riley, 1963). The perfusion pressure (PP) driving blood through the capillary circulations of the retina, choroid, and optic nerve head is therefore defined as the mean arterial blood pressure $\left(\mathrm{P}_{\mathrm{a}}\right)$ minus the intraocular pressure $\left(\mathrm{P}_{\mathrm{i}}\right)$-that is, $\mathrm{PP}=\mathrm{P}_{\mathrm{a}}-\mathrm{P}_{\mathbf{i o}}$.

A reduction in blood flow thus follows obstruction of the central retinal or posterior ciliary arteries, though the effects on perfusion may be counteracted by autoregulatory changes in the calibre of precapillary resistance vessels which tend to maintain blood flow despite changes in perfusion pressure (Alm and Bill, 1972). Ischaemic changes occur in the inner retina, outer retina, or optic nerve head when, despite autoregulatory vasodilatation and collateral flow, capillary perfusion is insufficient to meet the individual metabolic requirements of the various ocular tissues.

Obstruction of the vortex or retinal veins also causes a reduction in blood flow $\left(\mathrm{PP}=\mathrm{P}_{\mathrm{a}}-\mathrm{P}_{\mathrm{v}}\right)$, while the increase in transmural pressure across small vessels is an important determinant of transudation and haemorrhage formation. Passive dilatation of capillaries and venules may reduce their flow-resistance after venous obstruction (Phillips, Brind, and Levy, 1955; Folkow, 1962), but the autoregulatory responses of precapillary arterioles after retinal vein occlusion have not been established. Increased transmural pressure gradients might be expected to result in arteriolar constriction due to a local myogenic reflex (Bayliss, 1902); alternatively, vasodilatation might be expected in response to retinal hypoxia and accumulation of metabolites after severe venous occlusion-'metabolic autoregulation'.

The increase in intraluminal pressure in the major retinal veins after central vein occlusion depends upon the change in venous outflow resistance and also upon the arterial blood pressure (since this determines the maximum venous pressure attainable). Total obstruction to retinal venous outflow has been achieved experimentally by neoprene latex occlusion of the central vein and potential retino-ciliary bypass channels (Fujino, Curtin, and Norton, 1969). The central venous pressure presumably approached the systolic arterial pressure in these animals and a haemorrhagic retinal infarct resulted. Central vein obstructions are seldom associated clinically with a complete failure of retinal perfusion. Hart and others (197I) have suggested that the central venous pressure approaches the diastolic arterial pressure, but Duke-Elder and Gloster (1968) emphasized that ophthalmodynamometry is unsuitable for assessing either arterial or venous pressures within the eye.

\section{PATHOGENESIS OF CILIO-RETINAL INFARCTION}

Symptoms and signs of venous obstruction and retinal ischaemia were recent in all our cases, suggesting that these events occurred simultaneously and probably interdependently. Furthermore, in case I I retinal infarction developed only in that part of the cilio-retinal territory which was drained by the obstructed branch vein, indicating that retinal ischaemia was precipitated by venous occlusion.

We have assumed that the metabolic requirements of the inner retina were the same in the central retinal and cilio-retinal territories and that identical blood flowed through similar capillary beds. Furthermore, impaired cilio-retinal perfusion was considered the cause and not the result of retinal infarction. Given that the central retinal and cilio-retinal supplies both drain into the central retinal vein, the localized severe reduction in cilioretinal perfusion must reflect either an increased resistance to blood flow along the cilio-retinal arterioles (compared with the central retinal arterioles) or a relatively low driving pressure in the posterior ciliary supply.

\section{(a) Increased resistance to flow}

Precapillary arterioles in the central retinal and cilio-retinal circulations may differ in their autoregulatory responses to venous occlusion. However, it is unlikely that retinal infarction resulted from a localized failure of metabolic 
autoregulation in the cilio-retinal circulation, and an exaggerated reflex constriction of cilio-retinal arterioles (Bayliss effect) is not in keeping with known autoregulatory responses in branches of the posterior ciliary vessels (Alm and Bill, 1972).

Alternatively, the selective severe impairment of cilio-retinal perfusion in these cases might reflect a relatively high 'vasomotor tone' in the posterior ciliary and cilio-retinal arteries, as postulated by Blumenthal, Best, Galin, and Gitter (1971). However, any conclusions drawn from ophthalmodynamoangiographic studies are open to question (Archer, Ernest, and Krill, 1972).

\section{(b) Reduction in input arterial pressure}

A lower driving pressure in the posterior ciliary arteries relative to that in the central artery could result in a localized failure of cilio-retinal perfusion after central vein occlusion. The cilio-retinal arterial pressure might approximate to a raised venous pressure sustained by the input pressure in the larger central arterial supply; the arteriovenous perfusion pressure gradient in the cilioretinal circulation would thus be effectively eliminated.

Unfortunately, there is no satisfactory clinical method of quantifying or comparing input arterial pressures in the various ocular circulations (DukeElder and Gloster, 1968) and therefore no good evidence of whether the pressure in the posterior ciliary supply differs appreciably from that in the central retinal artery in normal individuals. The failure of cilio-retinal perfusion in our cases might reflect some anatomical variation-for example, an unusually distal origin of the ciliary supply from the ophthalmic artery, or an exceptionally long extraocular course or peculiar pattern of branching of the posterior ciliary vessels.

Alternatively, this clinical picture may result from central vein occlusion in patients who have a pre-existing asymptomatic obstruction to flow in the posterior ciliary circulation which is insufficient in itself to produce ischaemic changes in the outer retina, optic nerve head, or cilio-retinal territory. Such a partial arterial obstruction might reflect the presence of generalized vascular disease in patients who develop retinal vein occlusions. Simultaneous infarction of all cilio-retinal territories in patients with multiple cilio-retinal arterioles indicates that any localized obstruction to flow must have been situated proximal to the emergence of these vessels from the optic disc, and the peripapillary choroidal filling defects could be interpreted as indicating an associated reduction in choroidal blood flow. However, although the central retinal vein is the major efferent channel from the optic disc (Hayreh, 1963b; Anderson, 1970), symptoms of ischaemic disc-swelling were lacking in several of our cases, presumably owing to the utilization of alternative drainage pathways from the disc into choroidal or pial veins; dilatation of these channels is part of the process of retino-ciliary collateral formation (Hayreh, 1969). In this way isolated infarction of the cilio-retinal territories reflected the fact that the cilio-retinal circulation is the only part of the posterior ciliary supply that depends entirely on the central vein for drainage.

\section{Conclusions}

Central vein occlusion in patients with partial obstruction of their posterior ciliary arteries may be the explanation for at least some of our cases, though the relative contribution of reduced ciliary arterial pressure and raised venous pressure to cilio-retinal ischaemia probably varied from patient to patient. In some cases a critical reduction in cilio-retinal perfusion resulted from a degree of central vein obstruction that caused few exudative or haemorrhagic sequelae in the central retinal territory. Indeed, some patients might not have presented had they not possessed a cilio-retinal arterial supply, since central vein occlusion often produces minimal symptoms in the absence of macular oedema (Hart and others, 1971).

Although experimental central vein occlusion is known to cause severe retinal ischaemia (Fujino and others, 1969) the relationship between retinal infarction and venous occlusion is less clearly defined clinically. These cases show that under certain conditions venous occlusion may result in acute retinal infarction in the absence of significant haemorrhage or extracellular oedema.

This series may represent a spectrum of ocular vascular lesions intermediate between acute central retinal vein occlusion and acute ischaemic optic neuropathy (which is commonly associated with peripapillary haemorrhages and venous dilatation).

\section{Summary}

Retinal ischaemia in the territory supplied by cilio-retinal arterioles is described in 10 patients with signs of central retinal vein occlusion and in another patient with a hemisphere branch vein occlusion. The venous occlusion was transitory in nine of the I I cases, but two elderly patients developed rubeotic glaucoma.

We thank Mr A. C. Bird, Mr R. K. Blach, Dr J. F. Cullen, Mr L. G. Fison, Dr Eva Kohner, and Mr M. D. Sanders for allowing us to report details of their cases. We are indebted to Mr K. Sehmi and Mr G. Gosai, of the Retinal Diagnostic Unit, Moorfields Eye Hospital, for the illustrations, and to Miss L. Martin and Miss I. F. Miller for secretarial assistance. 


\section{References}

ALM, A., and BILl, A. (1972) Acta physiol. scand., 84, 306

ANDERSON, D. R. (1970) Amer. F. Ophthal., 70, 341

ARCHER, D., ERNEST, J. T., and KRILL, A. E. (I972) Ibid., 73, 834

Bayliss, w. M. (1902) F. Physiol. (Lond.), 28, 220

Blumenthal, M., BeSt, M., Galin, M. A., and GitTer, k. A. (I97I) Amer. J. Ophthal., 71, 819

DUKE-ELDER, S., and GLOSTER, J. (1968) In 'System of Ophthalmology', vol. IV. Kimpton, London

Folkow, B. (1962) Arch. int. Pharmacodyn., 139, 455

Fujino, T., Curtin, v. T., and Norton, E. W. (1969) Arch. Ophthal. (Chic.), 81, 395

HART, C. D., SANDERS, M. D., and MILlER, S. J. H. (I97I) Brit. F. Ophthal., 55, 72 I

HAYREH, S. S. (1963a) Ibid., 47, 7I

( (963b) Ann. Inst. Barraquer, 4, 7

(1969) Brit. F. Ophthal., 53, 72 I

(1971) Amer. J. Ophthal., 72, 998

(1972) Brit. F. Ophthal., 56, 652

LONN, L. 1., and hOYт, w. F. (1966) Eye, Ear, Nose, Thr. Monthly, 45, 62

LYLE, T. K., and WYBAR, K. (1961) Brit. F. Ophthal., 45, 778

MCLEOD, D. (1975a) Lancet, 2, 954

(1975b) Brit. F. Ophthal., 59, 486

(1976) Ibid., 60, in press

oosterhuis, J. A. (I 968) In 'Perspectives in Ophthalmology', p. 29, ed. H. E. Henkes. Excerpta Medica

Foundation, Amsterdam

PERMUTt, S., and RILey, R. L. (1963) F. appl. Physiol., 18, 924

PHILliPS, F. A., BRIND, S. H., and LEVY, M. H. (1955) Circulat. Res., 3, 357 